\title{
Provision of supplementary food for wild birds may increase the risk of local nest predation
}

Article

Accepted Version

Hanmer, H. J., Thomas, R. L. and Fellowes, M. D. E. (2017) Provision of supplementary food for wild birds may increase the risk of local nest predation. Ibis, 159 (1). pp. 158-167. ISSN 0019-1019 doi: https://doi.org/10.1111/ibi.12432 Available at https://centaur.reading.ac.uk/68066/

It is advisable to refer to the publisher's version if you intend to cite from the work. See Guidance on citing.

To link to this article DOI: http://dx.doi.org/10.1111/ibi.12432

Publisher: Wiley

All outputs in CentAUR are protected by Intellectual Property Rights law, including copyright law. Copyright and IPR is retained by the creators or other copyright holders. Terms and conditions for use of this material are defined in the End User Agreement.

$\underline{\text { www.reading.ac.uk/centaur }}$

\section{CentAUR}


Central Archive at the University of Reading

Reading's research outputs online 


\title{
Provision of supplementary food for wild birds may increase the risk of local nest predation
}

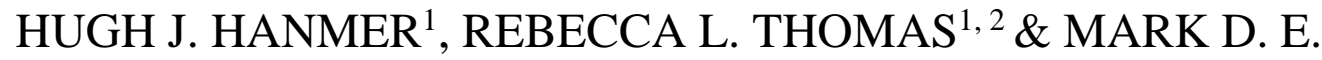 \\ FELLOWES $^{1 *}$
}

${ }^{1}$ People and Wildlife Research Group, School of Biological Sciences, Harborne Building, University of Reading, Whiteknights, Reading, Berkshire, RG6 6AS, UK

${ }^{2}$ School of Biological Sciences, Royal Holloway, University of London, Egham, Surrey, TW20 OEX, UK

* Corresponding author.

Email: $\underline{\text { m.fellowes@ reading.ac.uk }}$

In countries such as the UK, USA and Australia, approximately half of households provide supplementary food for wild birds, making this the public's most common form of active engagement with nature. Year round supplementary feeding is currently encouraged by major conservation charities in the UK as it is thought to be of benefit to bird conservation. However, little is understood of how the provision of supplementary food affects the behaviour and ecology of target and non-target species. Given the scale of supplementary feeding, any negative effects may have important implications for conservation. Potential nest predators are abundant in urban areas and some species frequently visit supplementary feeding stations. We asked if providing supplementary food affected the likelihood of nest predation in the vicinity of the feeder, by acting as a point attractant for potential nest predators. We provided feeding stations (empty, peanut feeder, peanut feeder with guard to exclude potential nest predators) in an area of suburban parkland in the UK and monitored the predation rate experienced by eggs placed in artificial nests located at distances which replicate the size of typical suburban gardens. Nest predators (Magpies Pica pica, Grey Squirrels Sciurus carolinensis) were frequent visitors to filled feeders, and predation caused by Magpies, European Jays Garrulus glandarius and Grey Squirrels was significantly higher when nests were adjacent to filled feeders. The presence of a feeder guard did not significantly reduce nest predation. As supplementary feeding is becoming increasingly common during the breeding season in suburban habitats, we suggest that providing point attractants to nest predators at this time may have previously unconsidered consequences for the breeding success of urban birds.

Keywords: artificial nest, predation, bird feeding, garden, corvid, Grey Squirrel, Eurasian Magpie, 
41 Garden bird feeding engages more people with wildlife than any other activity. Some $48 \%$ of households in Britain (Davies et al. 2009) and 53 million households in the USA feed wild birds (U.S. Fish and Wildlife Service 2011), providing an enormous and highly localised additional food resource. For example, in suburban Reading, UK, over 55\% of householders provide supplementary food for wild birds, two-thirds of whom feed year round (Orros \& Fellowes 2015a). The majority of individuals provide peanuts, a range of seed types (e.g. sunflower, nyger, wheat) and fat to birds visiting their gardens. A conservative estimate suggests that enough food is annually provided in the UK to support over 30 million garden birds (Orros \& Fellowes 2015a). This is reflected by the size of the bird feeding industry, which ten years ago was estimated to be worth $£ 200$ million per annum (British Trust for Ornithology 2006). This figure is likely to be considerably higher today.

Supplementary feeding in urban areas affects the abundance and distribution of species as diverse as the Red Kite Milvus milvus (Orros \& Fellowes 2014, 2015b), hummingbirds (Hill et al. 1998, Courter et al. 2013) and the Blackcap Sylvia atricapilla (Chamberlain et al. 2005, Rolshausen et al. 2009, Plummer et al. 2015). While feeding has been shown to increase adult overwinter survival (Jansson et al. 1981, Brittingham \& Temple 1988), effects on bird productivity are variable, and overwinter supplementary feeding has been found to both increase (Robb et al. 2008) and decrease (Plummer et al. 2013a, b) breeding success in subsequent seasons. Similarly, supplementary feeding experiments during the breeding period have found mixed results, with evidence for both decreases (Harrison et al. 2010) and increases (Peach et al. 2013, Smith \& Smith 2013) in productivity. Furthermore, feeding stations may facilitate the transmission of disease (Bradley \& Altizer 2007), which can lead to rapid population declines (e.g. trichomonosis in greenfinch; Robinson et al. 2010).

Urban birds tend to lay eggs earlier, have smaller clutch sizes, lower nestling weight and lower productivity per nesting attempt (Chamberlain et al. 2009). Open-cup nesters decline with increasing urbanisation but remain part of the avifauna (Máthé \& Batáry 2015) and UK gardens hold significant populations of several such species (Bland et al. 2004). While food availability and habitat suitability 
predation is a key cause of nest failure for open-cup nesters (Ricklefs 1969, Martin \& Li 1992), possibly also limiting their populations (Jokimaki \& Huhta 2000). Predator densities in urban areas may be higher than in rural areas for some nest predators, such as corvids (Jokimaki \& Huhta 2000, Antonov \& Atanasova 2003, Jokimäki et al., 2005, Sorace \& Gustin 2009), although it is unclear if this apparent increase in potential predator density depresses prey populations (Shochat 2004, Madden et al. 2015). Eurasian Magpies Pica pica and introduced Grey Squirrels Sciurus carolinensis are common in UK urban areas and are frequent nest predators (Eaton et al. 2013, Bonnington et al. 2014a). Increased nest predation in an urban area is associated with increased corvid density, although no association was found with grey squirrel population size (Bonnington et al. 2015).

Nest predators, such as Eurasian Magpies and Grey Squirrels, can be attracted by garden feeding stations (Chamberlain et al. 2005, Väisänen 2008, Bonnington et al. 2014b). As a result, those providing supplementary food can also purchase caged feeders, which aim to exclude larger species, including squirrels and corvids. At a domestic garden scale the provision of bird feeders reduces the local abundance of insects (Orros \& Fellowes 2012, Orros et al. 2015), and the provision of supplementary food for ungulates (Cooper \& Ginnett 2000, Selva et al. 2014) and woodland predators (Borgmann et al. 2013) increased local nest predation. In each case the supplementary food appears to attract predators to a point source, which in turn foraged locally on other prey. The most parsimonious explanation is that the presence of a reliable or high quality food resource both increases the numbers of potential nest predators and the time they spend foraging near the food source.

It is not known if supplementary feeding of the type practised by tens of millions of garden owners increases the risk of local nest predation in urban and suburban habitats. These habitats support significant populations of native bird species in the UK including a number of open-cup nesting species that have undergone national declines in recent decades, such as the Blackbird (Turdus merula), the Dunnock (Prunella modularis), and the UK red-listed Song Thrush (Turdus philomelos) (Gregory \& Baillie 1998, Bland et al. 2004). Given the near ubiquity of supplementary feeding in urban areas, and the recommendation from bird conservation NGOs (e.g. RSPB 2009) to feed birds throughout the year, it is possible that individuals providing supplementary food in their gardens are 
inadvertently increasing nest predation rates suffered by their garden birds. To investigate this further it is first necessary to establish if nest predation is elevated near bird feeding stations. By using both guarded (food inaccessible to nest predators) and unguarded feeders (food accessible), we can test if it is the presence of food (both accessible and inaccessible) or the availability (food accessible in unguarded feeders) of food which affects predation rates.

Studying nest predation using real nests would result in considerable practical and ethical challenges. As a result, artificial nests provide an important tool for studying bird nest predation (Major \& Kendal 1996, Miller \& Hobbs 2000). Typically nests are baited with quail and/or model eggs and monitored over a set period. Artificial nests are undefended by adults and lack the activity of real nests; nevertheless, they provide experimental nest predation data at scales which would be difficult to achieve in natural studies, while avoiding the ethical issues of experimenting with natural nests (Major \& Kendal 1996, Moore \& Robinson 2004). Using camera monitored artificial nests we investigated nest survival around caged, uncaged and empty bird feeders. Our objectives were to determine if a) potential nest predators were attracted to bird feeding stations providing supplementary food, b) if so, if this was associated with differences in rates of nest predation, c) if increased nest predation was associated with access to food (unguarded feeders) or the presence of food (guarded and unguarded feeders) and d) if nest predation rates were affected by distance from the supplementary food source.

\section{Materials and methods}

\section{Study area}

The study was conducted at the University of Reading's Whiteknights Campus (UK; 5127’ N, $\left.0^{\circ} 58^{\prime} \mathrm{W}\right)$, in an area of open parkland and woodland comprising approximately $68 \%$ natural surfaces overall, embedded in a typical UK suburban landscape broadly conforming to Marzluff et al. (2001). The town of Reading covers approximately $40 \mathrm{~km}^{2}$ with a population of 230000 people (Office for National Statistics 2013). 
Experimental work was carried out between the $5^{\text {th }}$ of May and the $17^{\text {th }}$ of June 2014 , which is during

121 the peak bird breeding season for the UK (Robinson 2005). Fifty-four locations were selected on the

122 edge of grassy clearings and open spaces with adjacent areas of shrubs and bushes, $50-100 \mathrm{~m}$ apart, replicating typical suburban feeder distribution (Fuller et al. 2008). The experiment consisted of six two-week sample cycles. During each cycle, nine peanut feeders (CJ Wildlife small defender feeder, Shrewsbury, UK) were positioned (three each of empty, filled and unguarded, filled and fitted with a cage guard). Feeders were randomly placed in each of the study locations, one week before the nests, to allow habituation. Sites were not reused and all were at least $20 \mathrm{~m}$ away from the closest building. Experimental cycles were staggered at one week intervals to reduce the sampling time required for the whole experiment.

Two artificial nests were placed diametrically opposed ca. 5m ('near') and 10m ('far') from each feeder $( \pm 1 \mathrm{~m})$, replicating typical distances between feeders and suburban garden boundaries (Gaston et al. 2007). In total 108 nests were placed (one 'near', one 'far', at each of the 54 feeder locations). Nests were constructed of $15 \times 15 \mathrm{~cm}$ squares of small-gauge wire mesh lined with dried grass and attached to branches to imitate a Blackbird nest (Kurucz et al. 2010, Kurucz et al. 2012). Nest height was at $1.5 \pm 0.5 \mathrm{~m}$ and were placed to mimic natural blackbird nest-sites and attempted to provide similar visual accessibility to potential predators following Swanson et al. (2012). Two fresh Quail Coturnix japonica eggs were placed in each nest (Buler \& Hamilton 2000). Blackbirds are a common breeding species in UK gardens along with the less common but similarly sized Song Thrush (Bland et al. 2004), making them an appropriate species to simulate. Nests were monitored for seven days (168 hours) as $90 \%$ of predation events occur within 6 days of placement (Burke et al. 2004).

Each nest was continually monitored by a concealed motion-triggered camera trap (Ltl Acorn 5310;

142 Ltl Acorn Inc, USA), set to the highest sensitivity setting, taking three photographs with a three second interval when triggered.

144 Feeders were checked every 3.5 days and refilled where necessary. Feeder usage was sampled using camera traps, but each was monitored for 3.5 days either at the beginning or end of the week to ensure 
coverage with limited traps. At any one time one of each feeder type was monitored and two thirds of

147 all feeders were sampled for usage.

148 Nest fate was recorded and for predated nests, predation time and predator identity determined. Any

149 damage to or removal of eggs was considered a predation event. Visitation rates per species were recorded at the feeders; as visitors could not be individually identified, a visitor was considered an individual when either separated by a photograph without the animal or when four or more minutes had elapsed without a feeding event.

Data Analysis

All analyses were carried out within the program R (R Core Team 2016), with nest survival tested using Cox's proportional hazard model in base R survival package (version 2.39-4, Therneau 2015). This approach was used over a logistic exposure or regression approach (Shaffer 2004) because exact survival time and fate was known for each nest and exposure period did not vary. Covariates were feeder type (empty, guarded, unguarded), distance from feeder (near, far) and study week block (as a random effect) with time until predation (hours) and predation status as response variables. No interaction terms were used. We evaluated the relative fit of each candidate model using Akaike's Information Criterion with a small-sample bias adjustment, comparing models using Akaike weights and delta AICc (Burnham \& Anderson 2002).

Mean daily feeder visitation (as a proxy for usage) was first compared using Kruskal-Wallis tests between treatment, by individual species, all potential 'predator' species, all small birds and all animals. Binomial logistic mixed model regression was then used to test for specific relationships between animal feeder usage and predation overall. Two separate global models were constructed both with study week block as a random effect factor and whether a nest was predated as the binomial response variable in the $\mathrm{R}$ lme4 package (version 1.1-12, Bates et al 2015). First, a model that considered overall predator visits and small bird visits to feeders as variables effecting nest predation. Second, a model considering feeder visits by Squirrels, Magpies and small birds as variables effecting nest predation. Because Magpie and squirrel visits are subsets of overall predator visits it is not 
172 possible to utilise species and overall visits in the same model. Jays were not included in the

173 individual models due to their infrequent visits. Relative model fit was then separately evaluated using

174 delta AICc and Akaike weights for both global models as above against a null model containing only

175 the intercept and study week as a random factor. There was insufficient data to effectively compare

176 effectors on predation for individual predator species or at specific feeder types.

177 Results

178

179

180

181

182

183

184

185

186

187

188

189

190

191

192

193

194

195

196

\section{Feeder visitation}

Thirty-three of the 54 feeders were monitored (10 empty, 11 guarded, 12 unguarded). Eleven species were recorded making 5251 individual feeder visits (empty feeders: 17; guarded: 3522; unguarded: 1712 visits).

Grey Squirrels contributed $43.9 \%$ of visits to unguarded and $9.3 \%$ of visits to guarded feeders while smaller birds were more likely to visit guarded feeders (Table 1). Magpies were a regular visitor to unguarded feeders but rare at empty and guarded feeders. One exception was an individual guarded feeder, which did receive frequent visits (Figure 1). Despite predating $27.5 \%$ of all recorded nests, Jays only visited feeders eight times. All species visiting more than two individual feeders (excluding unknowns) show a significant difference between their feeder usages (Table 1; Figure 1).

\section{Nest survival}

Of the 108 experimental nests, 102 were successfully monitored, with 74 recorded predation events (magpie: 37; jay: 28; grey squirrel: 8 ; one unknown). Six nest predation events were missed due to camera errors or human interference and so were omitted from the analysis ( 3 empty, 2 guarded and 1 unguarded). From the different feeder types $51.5 \%$ of empty feeder nests, $76.5 \%$ of guarded feeder nests and $88.6 \%$ of unguarded feeder nests were predated during the course of the experiment. No predation events were recorded between 20:10 and 05.32.

When AICc selection was carried out on the global hazard model, the AICc selected model with distance from feeder removed had a delta AICc of less than 2 from the global model so for 
completeness we present both the global (Wald $=23.05$, d.f. $=6.42, \mathrm{p}<0.001, \mathrm{AICc}=600.4$, model weight $=0.210 ;$ Table 2$)$ and AICc selected model $($ Wald $=22.93$, d.f. $=5.43, \mathrm{p}<0.001$, AICc $=$ 598.5, model weight $=0.672$; Table 2). Separate post hoc ANOVAs of both models (following Therneau 2015) found feeder type and week were significant effectors of nest survival overall $\left(\chi^{2}=\right.$ 11.8 , d.f. $=2, \mathrm{p}=0.003$ and $\chi^{2}=17.6$, d.f. $=3.4, \mathrm{p}<0.001$ for feeder type and study week respectively in both models). In both models nests near filled feeders were significantly more likely to be predated than those near empty feeders and week was a significant covariate with identical hazard ratios after rounding (Table 2; Figure 2). Nest distance from feeder did not significantly affect predation rates in the global model $(\mathrm{p}=0.67)$ and was eliminated in the AICc selected model (Table 2). No significant difference in survival was found between nests adjacent to guarded and unguarded feeders (post-hoc Tukey test $\mathrm{p}=0.82$; Figure 2).

\section{Nest predation and feeder usage}

Overall feeder activity by predators (Grey Squirrels, Jays and Magpies) was significantly associated with increased nest predation (Wald $\mathrm{Z}=2.518, \mathrm{p}=0.019$ ) in the AICc selected mixed effect model (Table 3). In the model considering individual predator usage, Grey Squirrel usage was significantly associated with increased overall nest predation (Wald $\mathrm{Z}=2.305, \mathrm{p}=0.021$ ) in the AICc selected model (Table 3). However, support for this model is weak with little separation between all possible model AICcs and similar Akaike weights in several models (Table 3). Usage by small birds was not a significant factor in any model (Table 3).

\section{Discussion}

We that the provision of supplementary food during the breeding season for wild birds in a form common in urban and suburban habitats may increase the likelihood of local nest predation. The survivorship of nests adjacent to unguarded feeders was less than $20 \%$ of that seen when artificial nests were placed near empty feeders. There was no difference in nest survival near guarded feeders when compared with those placed adjacent to unguarded feeders. Increased predation was associated 
with Magpies, Jays and Grey Squirrels. Magpies and Grey Squirrels were significantly more likely to visit unguarded feeders, while Jays were largely absent. Overall, nest predation was associated with increased predator visits, particularly by Grey Squirrels, to feeders. There was no effect on nest predation rates of distance to feeder at the scales we considered. Species assemblages differed between treatments; empty feeders received few visits or no visits, guarded feeders were mostly visited by small passerines and unguarded feeders attracted a higher proportion of corvids and Squirrels. Despite being unable to feed at guarded feeders, predators still made up $9.4 \%$ of total visits to them. No mammalian nest predators other than Grey Squirrels were recorded despite being present at the study site and in UK urban areas generally (e.g. Brown Rat Rattus norvegicus, mice Apodemus spp., Red Fox Vulpes vulpes, Domestic Cats Felis catus: Baker \& Harris 2007, Thomas et al. 2012). Two nests recorded mouse visits but no predation attempts were observed.

Nests adjacent to filled feeders suffered greatly increased predation rates, with the majority of nest predation events caused by corvids (Magpies and Jays) and Grey Squirrels. Nest predation by corvids is a frequent occurrence in urban habitats (Jokimaki \& Huhta 2000, Thorington \& Bowman 2003, Jokimäki et al., 2005, Bonnington et al. 2015), where densities are high due to their omnivorous diet and adaptability, as well as reduced numbers of larger predators and/or competitors (Soh et al. 2002, Marzluff et al. 2007).

Despite our record of animal usage and clear evidence for an effect of the presence of supplementary food, the exact nature of the link between feeder usage and local nest predation remains unclear. There is a significant positive relationship overall between feeder usage by predators, in particular Grey Squirrels, and increased nest predation. Predation by Grey Squirrels themselves was lower than the two corvid species, suggesting there was not a direct link between Squirrel feeder usage and nest predation by Squirrels. We lack sufficient samples and model support to investigate this further, but we speculate that their presence at bird feeders may influence predation rates by Jays and Magpies. We propose two non-mutually exclusive mechanisms that may lead to this.

First, Jays and Magpies may be responding to the increased density of other omnivores which have been attracted by the presence of supplementary food. They in turn may be more likely to enter the 
feeder area, associating it with increased feeding potential, even if they themselves are not primary users of the bird feeders. In particular the frequency of Jay predation was unexpected due to their infrequent attendance at feeders, while Magpies did utilise feeders, but in low numbers. Second, the presence of Squirrels on feeders may exclude other omnivorous predators as well as small birds, resulting in increased foraging in the vicinity of the feeders, hence increasing local nest predation.

Taken together, these results suggest that feeder usage by nest predators is associated with increased predation on our experimental nests, but this effect is not simply a result of nest predators being attracted to a point source, but instead perhaps also by being attracted by other feeder users to the vicinity of the food source.

We tested to see if nest predation changed with distance from the feeder, but there was no effect. The distances chosen for the study (5 and 10 metres) were relatively small and are consistent with the layout of a typical UK suburban garden (Smith et al. 2006, Loram et al. 2007). However, we suggest that there could still be a distance effect. While not explicitly recorded, we observed no evidence of increased predation suffered by nests placed close to an empty feeder when the closest replicate was a filled feeder. Therefore we suggest that while the increased risk of nest predation is present when nests are within 10 metres of a feeder, this effect may be lost at a distance up to 40 metres away (the minimum distance between a feeder and the next closest nest associated with another feeder under our experimental design). Further testing over a larger range of distances with independent nests would be required to effectively test this theory.

The use of artificial nests does present some interpretive challenges (Buler \& Hamilton 2000, Burke et al. 2004, Moore \& Robinson 2004). They lack the odours, activity and defending adults of natural nests (Swanson et al. 2012). Concerns have also been raised over the use of Quail eggs in artificial nests, with suggestions that they may be too large for some small predators (Burke et al. 2004). This also means that artificial nests may not be representative of smaller common UK open cup nesting birds, such as Robins Erithacus rubecula and Dunnocks, in terms of egg and nest size as well as concealment. Some studies have substituted model eggs made from modelling clay, both to give a smaller prey item and so that when nests are not monitored by cameras it allows predator 
identification through marks left on the eggs (Major \& Kendal 1996, Burke et al. 2004). These studies have found that rodents (not including Squirrels) cause a significant proportion of artificial nest predation events. As only two nests were visited by mice and none by rats (and no feeder visits by rats were recorded) either the system in this experiment is different or previous results have been skewed by the attraction of these rodents to the smell and/or taste of the model eggs (Rangen et al. 2000). While for practical and ethical reasons the use of artificial nests remains the standard approach for understanding the causes and consequences of nest predation, such caveats suggest that interpreting the results of artificial nest studies should be taken as indicative rather than definitive, particularly when applied to bird species of different sizes or with different nesting habits such as ground or cavity nesting birds.

The urban landscape presents a challenging environment for wild birds to live and breed (Chace \& Walsh 2006, Chamberlain et al. 2009). Together with potentially limited natural food (McKinney 2008) and high numbers of generalist predators (Sorace \& Gustin 2009), urban areas also hold the majority of the UK's estimated 10.3 million Cats (Murray et al. 2010) which predate millions of birds annually (Thomas et al. 2012, Thomas et al. 2014). Nevertheless, significant populations of birds are supported within urban environments (Bland et al. 2004) and species richness can be greater than in adjacent rural areas (Chace \& Walsh 2006), in part because of the combined efforts of millions of people providing supplementary food (Fuller et al. 2008).

However, while some species are effectively human commensals, others including open-cup nesters such as thrushes, are increasingly under challenge in urban habitats (Máthé \& Batáry 2015) and do not necessarily use the supplementary food people supply. In consequence, supplementary feeding may strongly benefit one avian guild to the detriment of others through increased local nest predation. Any effect we have on their demographic processes through supplementary feeding may have important conservation consequences and warrants further investigation. However, while we have shown that nests close to filled feeders suffer considerably higher predation rates, it is not clear if such predation would affect the population dynamics of urban birds. As with other anthropogenic pressures (e.g. the presence of Cats), testing this would not be straight-forward, in particular given the ubiquity of 
supplementary feeding in urban ecosystems. Nevertheless, while difficult, this work suggests that the question is worthy of further exploration.

Furthermore, we find that feeder type affects the assemblage of species feeding upon it. When feeders are unguarded, corvids and Grey Squirrels exclude small passerines (this study; Bonnington et al. 2014a, Orros \& Fellowes 2015a). We suggest that this not only reduces the volume of food available to target species through competition, it may also support increased population sizes of predatory species through a demographic response (Davies et al. 2009). We suggest that people who choose to provide supplementary food for birds consider using guarded feeders to minimise opportunities to support predatory species, and consider in the context of the ecology of their own gardens if feeding during the breeding season is appropriate.

Providing supplementary food during the breeding season is widespread (Orros \& Fellowes 2015a) and can increase local bird population size (Peach et al. 2013, Smith \& Smith 2013). Urban areas may be important for the conservation of some bird species and species richness in suburban areas can be greater than that found in adjacent urban and rural areas largely as a result of the decisions made by millions of homeowners (Marzluff 2001, Chace \& Walsh 2006, Väisänen 2008, Jokimäki \& Kaisanlahti-Jokimäki 2012). Our results suggest a possible negative indirect effect of supplementary garden bird feeding on local nesting success by attracting nest predators to point sources of food. It would be unfortunate if our most common act of engagement with wildlife was counter-productive during the breeding season.

\section{Acknowledgements}

This work was supported by a studentship funded by the Keith Duckworth Trust and Songbird Survival. The funders had no role in study design, data collection and analysis, decision to publish, or preparation of the paper. We thank anonymous reviewers whose comments greatly improved the manuscript. 


\section{References}

331

332

333

334

335

336

337

338

339

340

341

342

343

344

345

346

347

348

349

350

351

352

353

354

355

356

357

358

359

360

361

362

363

Antonov, A. \& Atanasova, D. 2003. Small-scale differences in the breeding ecology of urban and rural Magpies Pica pica. Ornis Fennica, 80: 21-30.

Baker, P. J. \& Harris, S. 2007. Urban mammals: what does the future hold? An analysis of the factors affecting patterns of use of residential gardens in Great Britain. Mammal Review, 37: 297 315.

Bates, D., Maechler, M., Bolker, B. \& Walker, S. 2015. Fitting linear mixed-effects models using lme4. Journal of Statistical Software, 67: 1-48.

Bland, R. L., Tully, J. \& Greenwood, J. J. D. 2004. Birds breeding in British gardens: an underestimated population? Bird Study, 51: 97-106.

Bonnington, C., Gaston, K. J. \& Evans, K. L. 2014a. Squirrels in suburbia: influence of urbanisation on the occurrence and distribution of a common exotic mammal. Urban Ecosystems, 17: 533546.

Bonnington, C., Gaston, K. J. \& Evans, K. L. 2014b. Assessing the potential for Grey Squirrels Sciurus carolinensis to compete with birds at supplementary feeding stations. Ibis, 156: 220226.

Bonnington, C., Gaston, K. J. \& Evans, K. L. 2015. Ecological traps and behavioural adjustments of urban songbirds to fine-scale spatial variation in predator activity. Animal Conservation, 16: 529-538.

Borgmann, K. L., Conway, C. J. \& Morrison, M. L. 2013. Breeding phenology of birds: mechanisms underlying seasonal declines in the risk of nest predation. Plos One, 8: 10.

Bradley, C.A. \& Altizer, S. 2007. Urbanization and the ecology of wildlife diseases. Trends in Ecology and Evolution, 22: 95-102.

British Trust for Ornithology. 2006. We spend $£ 200$ million a year on wild bird food. In British Trust for Ornithology Press Release No. 2006/12/76. Thetford: British Trust for Ornithology. 
Brittingham, M. C. \& Temple, S. A. 1988. Impacts of supplemental feeding on survival rates of Black-Capped Chickadees. Ecology, 69: 581-589.

Buler, J. J. \& Hamilton, R. B. 2000. Predation of natural and artificial nests in a southern pine forest. Auk, 117: 739-747.

Burke, D. M., Eliliott, K., Moore, L., Dunford, W., Nol, E., Phillips, J., Holmes, S. \& Freemark, K. 2004. Patterns of nest predation on artificial and natural nests in forests. Conservation Biology, 18: 381-388.

Burnham, K. P. \& Anderson, D. R. (2002) Model selection and multimodel inference: a practical information-theoretic approach, New York: Springer-Verlag.

Chace, J. F. \& Walsh, J. J. 2006. Urban effects on native avifauna: a review. Landscape and Urban Planning, 74: 46-69.

Chamberlain, D. E., Vickery, J. A., Glue, D. E., Robinson, R. A., Conway, G. J., Woodburn, R. J. W. \& Cannon, A. R. 2005. Annual and seasonal trends in the use of garden feeders by birds in winter. Ibis, 147: 563-575.

Chamberlain, D. E., Cannon, A. R., Toms, M. P., Leech, D. I., Hatchwell, B. J. \& Gaston, K. J. 2009. Avian productivity in urban landscapes: a review and meta-analysis. Ibis, 151: 1-18.

Cooper, S. M. \& Ginnett, T. F. 2000. Potential effects of supplemental feeding of deer on nest predation. Wildlife Society Bulletin, 28: 660-666.

Courter, J. R., Johnson, R. J., Bridges, W. C. \& Hubbard, K. G. 2013. Assessing migration of Rubythroated Hummingbirds (Archilochus colubris) at broad spatial and temporal scales. Auk, 130: 107-117.

Davies, Z. G., Fuller, R. A., Loram, A., Irvine, K. N., Sims, V. \& Gaston, K. J. 2009. A national scale inventory of resource provision for biodiversity within domestic gardens. Biological Conservation, 142: 761-771.

Eaton, M. A., Balmer, D. E., Bright, J., Cuthbert, R., Grice, P. V., Hall, C., Hayhow, D. B., Hearn, R. D., Holt, C. A., Knipe, A., Mavor, R., Noble, D. G., Oppel, S., Risely, K., Stroud, D. A. \& 
Wotton, S. 2013. The state of the UK's birds 2013. Sandy, Bedfordshire.: The RSPB, BTO, WWT, NRW, JNCC, NE, NIEA and SNH.

Fuller, R. A., Warren, P. H., Armsworth, P. R., Barbosa, O. \& Gaston, K. J. 2008. Garden bird feeding predicts the structure of urban avian assemblages. Diversity and Distributions, 14: $131-137$

Gaston, K. J., Fuller, R. A., Loram, A., MacDonald, C., Power, S. \& Dempsey, N. 2007. Urban domestic gardens (XI): variation in urban wildlife gardening in the United Kingdom. Biodiversity and Conservation, 16: 3227-3238.

Gregory, R. D. \& Baillie, S. R. 1998. Large-scale habitat use of some declining British birds. Journal of Applied Ecology, 35: 785-799.

Harrison, T. J. E., Smith, J. A., Martin, G. R., Chamberlain, D. E., Bearhop, S., Robb, G. N. \& Reynolds, S. J. 2010. Does food supplementation really enhance productivity of breeding birds? Oecologia, 164: 311-320.

Hill, G. E., Sargent, R. R. \& Sargent, M. B. 1998. Recent change in the winter distribution of Rufous Hummingbirds. Auk, 115: 240-245.

Jansson, C., Ekman, J. \& Anders von, B. 1981. Winter mortality and food supply in tits Parus spp. Oikos, 37: 313-322.

Jokimaki, J. \& Huhta, E. 2000. Artificial nest predation and abundance of birds along an urban gradient. Condor, 102: 838-847.

Jokimäki, J., Kaisanlahti-Jokimäki, M.-L., Sorace, A., Fernández-Juricic, E., Rodriguez-Prieto, I. \& Jimenez, M. D. 2005. Evaluation of the "safe nesting zone" hypothesis across an urban gradient: a multi-scale study. Ecography, 28: 59-70.

Kurucz, K., Kallenberger, H., Szigeti, C. \& Purger, J. J. 2010. Survival probabilities of first and second clutches of blackbird (Turdus merula) in an urban environment. Archives of Biological Sciences, 62: 489-493. 
Kurucz, K., Bertalan, L. \& Purger, J. J. 2012. Survival of blackbird (Turdus merula) clutches in an urban environment: experiment with real and artificial nests. North-Western Journal of Zoology, 8: 362-364.

Loram, A., Tratalos, J., Warren, P. H. \& Gaston, K. J. 2007. Urban domestic gardens (X): the extent $\&$ structure of the resource in five major cities. Landscape Ecology, 22: 601-615.

Madden, C. F., Arroyo, B. \& Amar, A. 2015. A review of the impacts of corvids on bird productivity and abundance. Ibis, 157: 1-16.

Major, R. E. \& Kendal, C. E. 1996. The contribution of artificial nest experiments to understanding avian reproductive success: A review of methods and conclusions. Ibis, 138: 298-307.

Martin, T. E. \& Li, P. 1992. Life History Traits of Open- vs. Cavity-Nesting Birds. Ecology, 73: 579592.

Marzluff, J. M., Bowman, R. \& Donnelly, R. 2001. A historical perspective on urban bird research: trends, terms, and approaches. In Avian Ecology and Conservation in an Urbanizing World. (eds. J. M. Marzluff, R. Bowman \& R. Donnelly), pp. 1-17. New York: Springer US.

Marzluff, J. M. 2001. Worldwide urbanization and its effects on birds. In Avian Ecology and Conservation in an Urbanizing World. (eds. J. M. Marzluff, R. Bowman \& R. Donnelly), pp. 19-47. New York: Springer US.

Marzluff, J. M., Withey, J. C., Whittaker, K. A., Oleyar, M. D., Unfried, T. M., Rullman, S. \& DeLap, J. 2007. Consequences of habitat utilization by nest predators and breeding songbirds across multiple scales in an urbanizing landscape. Condor, 109: 516-534.

Máthé, O. \& Batáry, P. 2015. Insectivorous and open-cup nester bird species suffer the most from urbanization. Bird Study, 62: 78-86.

McKinney, M. L. 2008. Effects of urbanization on species richness: A review of plants and animals. Urban Ecosystems, 11: 161-176.

Miller, J. R. \& Hobbs, N. T. 2000. Recreational trails, human activity, and nest predation in lowland riparian areas. Landscape and Urban Planning, 50: 227-236. 
Moore, R. P. \& Robinson, W. D. 2004. Artificial bird nests, external validity, and bias in ecological field studies. Ecology, 85: 1562-1567.

Murray, J. K., Browne, W. J., Roberts, M. A., Whitmarsh, A. \& Gruffydd-Jones, T. J. 2010. Number and ownership profiles of cats and dogs in the UK. Veterinary Record, 166: 163-168.

Office for National Statistics. 2013. Neighbourhood statistics. 2011 census data. HM Government. Crown Copyright. In 2011 census data. HM Government. Crown Copyright.

Orros, M. E. \& Fellowes, M. D. E. 2012. Supplementary feeding of wild birds indirectly affects the local abundance of arthropod prey. Basic and Applied Ecology, 13: 286-293.

Orros, M. E. \& Fellowes, M. D. E. 2014. Supplementary feeding of the reintroduced Red Kite Milvus milvus in UK gardens. Bird Study, 61: 260-263.

Orros, M. E. \& Fellowes, M. D. E. 2015a. Wild bird feeding in an urban area: intensity, economics and numbers of individuals supported. Acta Ornithologica, 50: 43-58.

Orros, M. E. \& Fellowes, M. D. E. 2015b. Widespread supplementary feeding in domestic gardens explains the return of reintroduced Red Kites Milvus milvus to an urban area. Ibis, 157: 230238.

Orros, M. E., Thomas, R. L., Holloway, G. J. \& Fellowes, M. D. E. 2015. Supplementary feeding of wild birds indirectly affects ground beetle populations in suburban gardens. Urban Ecosystems, 18: 465-475.

Peach, W. J., Mallord, J. W., Orsman, C. J., Ockendon, N. \& Haines, W. G. 2013. Testing assumptions of a supplementary feeding experiment aimed at suburban House Sparrows Passer domesticus. Bird Study, 60: 308-320.

Plummer, K. E., Bearhop, S., Leech, D. I., Chamberlain, D. E. \& Blount, J. D. 2013a. Fat provisioning in winter impairs egg production during the following spring: a landscape-scale study of blue tits. Journal of Animal Ecology, 82: 673-682.

Plummer, K. E., Bearhop, S., Leech, D. I., Chamberlain, D. E. \& Blount, J. D. 2013b. Winter food provisioning reduces future breeding performance in a wild bird. Scientific Reports, 3: 6. 
Plummer, K. E., Siriwardena, G. M., Conway, G. J., Risely, K. \& Toms, M. P. 2015. Is supplementary feeding in gardens a driver of evolutionary change in a migratory bird species? Global Change Biology, 21: 4353-4363.

R Core Team (2016) $R$ : A language and environment for statistical computing, Vienna, Austria.: $\mathrm{R}$ Foundation for Statistical Computing.

Rangen, S. A., Clark, R. G. \& Hobson, K. A. 2000. Visual and olfactory attributes of artificial nests. Auk, 117: 136-146.

Ricklefs, R. E. 1969. An analysis of nesting mortality in birds. Smithsonian Contributions to Zoology: $1-48$.

Robb, G. N., McDonald, R. A., Chamberlain, D. E., Reynolds, S. J., Harrison, T. J. E. \& Bearhop, S. 2008. Winter feeding of birds increases productivity in the subsequent breeding season. Biology Letters, 4: 220-223.

Robinson, R. 2005. BirdFacts: species profiles of birds occurring in Britain and Ireland. In BTO Research Report. Vol. 407. Thetford: BTO.

Robinson, R.A., Lawson, B., Toms, M.P., Peck, K.M., Kirkwood, J.K., Chantrey, J., et al. 2010. Emerging infectious disease leads to rapid population declines of common British birds. PLoS ONE, 5: e12215.

Rolshausen, G., Segelbacher, G., Hobson, K. A. \& Schaefer, H. M. 2009. Contemporary evolution of reproductive isolation and phenotypic divergence in sympatry along a migratory divide. Current Biology, 19: 2097-2101.

RSPB (2009) When to feed wild birds., Sandy, Bedfordshire: The Royal Society for the Protection of Birds.

Selva, N., Berezowska-Cnota, T. \& Elguero-Claramunt, I. 2014. Unforeseen effects of supplementary feeding: ungulate baiting sites as hotspots for ground-nest predation. Plos One, 9: e90740.

Shaffer, T. L. 2004. A unified approach to analyzing nest success. Auk, 121: 526-540. 
Shochat, E. 2004. Credit or debit? Resource input changes population dynamics of city-slicker birds. Oikos, 106: 622-626.

Smith, R. M., Thompson, K., Hodgson, J. G., Warren, P. H. \& Gaston, K. J. 2006. Urban domestic gardens (IX): Composition and richness of the vascular plant flora, and implications for native biodiversity. Biological Conservation, 129: 312-322.

Smith, K. W. \& Smith, L. 2013. The effect of supplementary feeding in early spring on the breeding performance of the great spotted woodpecker Dendrocopos major. Bird Study, 60: 169-175.

Soh, M. C. K., Sodhi, N. S., Seoh, R. K. H. \& Brook, B. W. 2002. Nest site selection of the house crow (Corvus splendens), an urban invasive bird species in Singapore and implications for its management. Landscape and Urban Planning, 59: 217-226.

Sorace, A. \& Gustin, M. 2009. Distribution of generalist and specialist predators along urban gradients. Landscape and Urban Planning, 90: 111-118.

Swanson, L., Sanyaolu, R. A., Gnoske, T., Whelan, C. J., Lonsdorf, E. V. \& Cordeiro, N. J. 2012. Differential response of nest predators to the presence of a decoy parent in artificial nests. Bird Study, 59: 96-101.

Therneau, T. M. (2015) A Package for Survival Analysis in S. R package version 2.37-7.

Thomas, R. L., Fellowes, M. D. E. \& Baker, P. J. 2012. Spatio-temporal variation in predation by urban domestic cats (Felis catus) and the acceptability of possible management actions in the UK. Plos One, 7: 13.

Thomas, R. L., Baker, P. J. \& Fellowes, M. D. E. 2014. Ranging characteristics of the domestic cat (Felis catus) in an urban environment. Urban Ecosystems, 17: 911-921.

Thorington, K. K. \& Bowman, R. 2003. Predation rate on artificial nests increases with human housing density in suburban habitats. Ecography, 26: 188-196.

U.S. Fish and Wildlife Service. 2011. National Survey of Fishing, Hunting, and Wildlife-Associated Recreation. 
582 Väisänen, R. A. 2008: Talviruokintapaikkojen lintujen seuranta 1989-2007. Linnut-vuosikirja, 2007: $583 \quad 60-79$.

584

585 


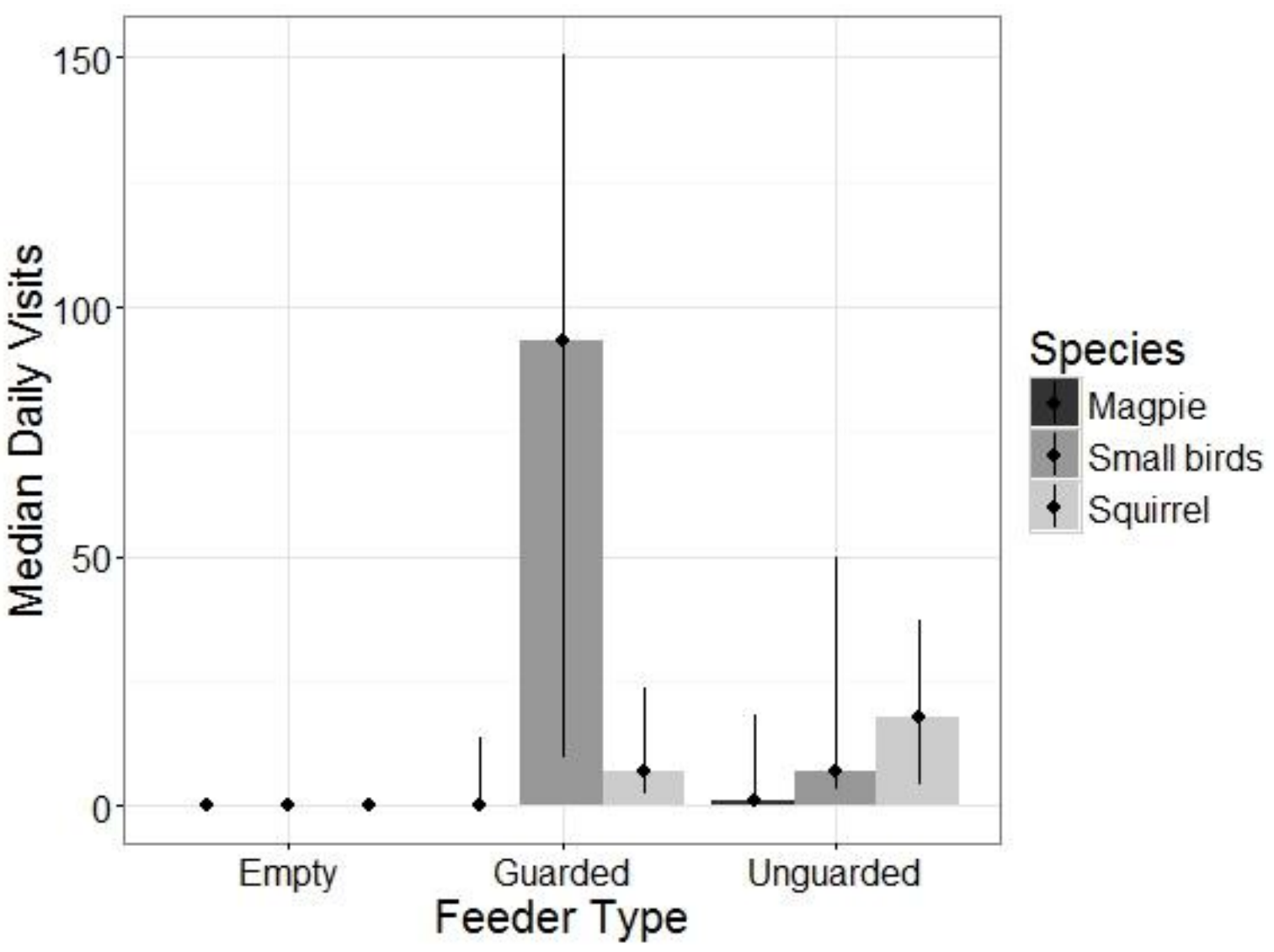

588 Figure 1. Median (+/-IQR) daily animal visits to each feeder treatment by species/grouping. Only species that 589 visited at least two individual bird feeders are included. Small bird species are great tit (Parus major), blue tit (Cyanistes caeruleus), nuthatch (Sitta europaea) and robin (Erithacus rubecula). 


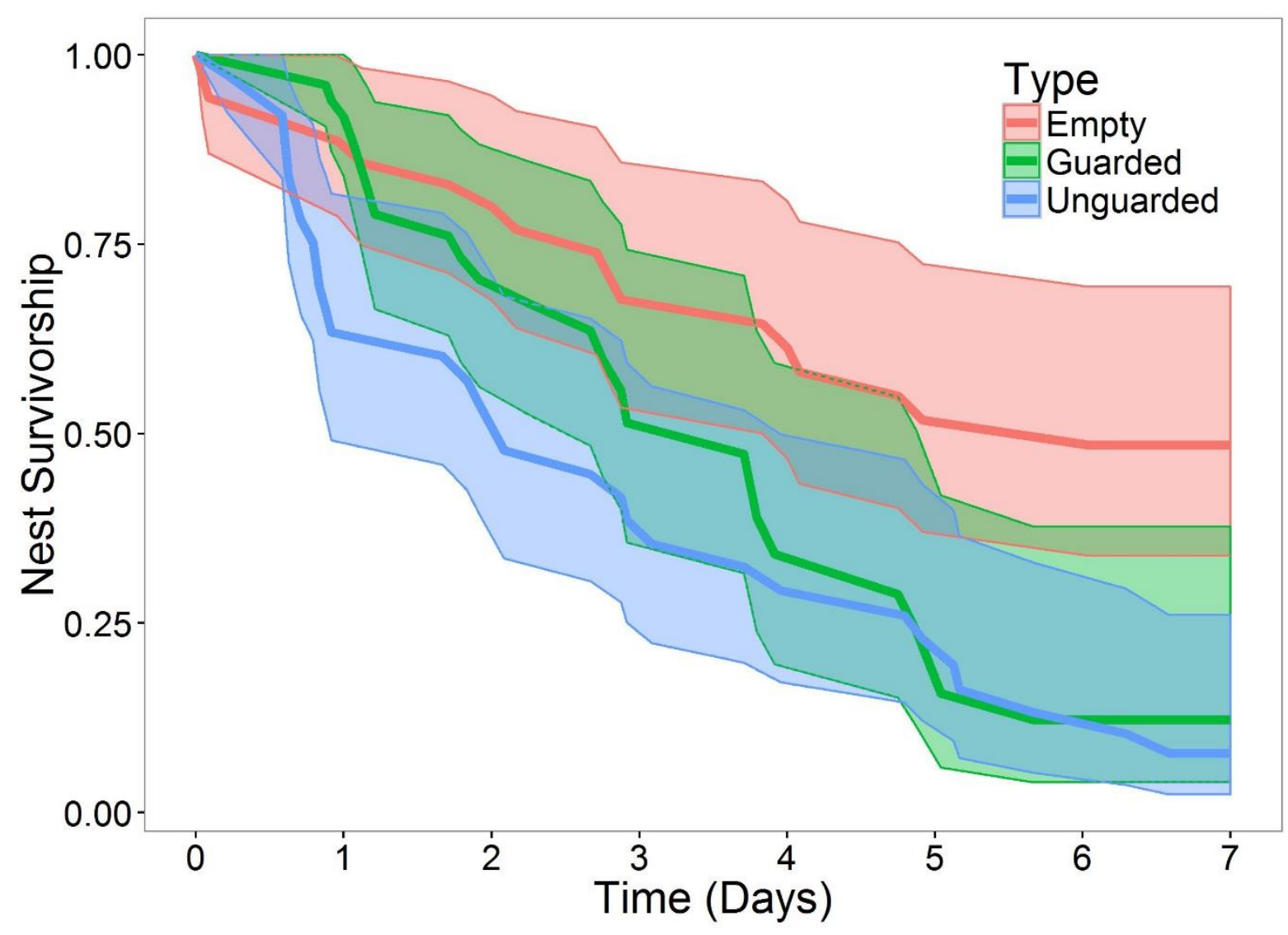

593 Figure 2. Predicted Cox's proportional hazard survival distribution by feeder nest type over the course of a 594 mean experimental week (bold lines) with individual 95\% confidence intervals (grey). Final predicted survival 595 rates were $0.49,0.12$ and 0.08 for empty, guarded and unguarded feeder nests respectively.

596

597

598

599

600

601

602 
Table 1. Median daily species visits and Kruskal-Wallis tests by feeder type (all d.f. $=2$ ). Only common species that visited at least two individual bird feeders are included.

\begin{tabular}{|c|c|c|c|c|c|c|}
\hline Species & $\begin{array}{l}\text { Empty } \\
\text { median }\end{array}$ & $\begin{array}{c}\text { Guarded } \\
\text { median }\end{array}$ & $\begin{array}{c}\text { Unguarded } \\
\text { median }\end{array}$ & $\begin{array}{c}\text { Kruskal-Wallis } \\
\text { chi-squared }\end{array}$ & $\mathbf{P}$ & $\begin{array}{c}\text { Number of } \\
\text { feeders where } \\
\text { species was } \\
\text { recorded }\end{array}$ \\
\hline Grey Squirrel & 0.0 & 6.9 & 17.86 & 23.02 & $<0.001$ & 26 \\
\hline Magpie & 0.0 & 0.0 & 0.9 & 6.88 & 0.032 & 13 \\
\hline Great Tit & 0.0 & 47.7 & 4.1 & 25.59 & $<0.001$ & 27 \\
\hline Blue Tit & 0.0 & 24.6 & 1.6 & 18.18 & $<0.001$ & 21 \\
\hline Nuthatch & 0.0 & 4.9 & 0.0 & 13.76 & 0.001 & 14 \\
\hline Robin & 0.0 & 0.3 & 0.0 & 8.12 & 0.017 & 14 \\
\hline
\end{tabular}

605 
Table 2. Hazard ratios (relative predation risk; $+/-\mathrm{CI}$ ) and $\mathrm{P}$ values for covariates in the global model where $\mathrm{h}=$

608

609

610

611

612

613

614

615

616

617

618

619

620

621

622

1 is the control (empty) feeder hazard ratio (d.f. $=6.42, \mathrm{AICc}=600.4$, model weight $=0.210$ ). After the removal of distance from the AICc selected model (d.f. = 5.43, AICc $=598.5$, model weight $=0.672)$ the hazard ratios,

$\mathrm{CI}$ and $\mathrm{P}$ values were identical after rounding.

\begin{tabular}{|l|l|l|l|l|}
\hline Covariate & Hazard ratio (h) & Lower 95\% CI & Upper 95\% CI & P \\
\hline Guarded & 2.14 & 1.14 & 3.99 & 0.017 \\
\hline Unguarded & 3.09 & 1.67 & 5.73 & $<0.001$ \\
\hline $\begin{array}{l}\text { Week } \\
\text { (random effect) }\end{array}$ & 1.00 & 0.58 & 1.73 & 0.010 \\
\hline $\begin{array}{l}\text { Distance } \\
\text { removed in } \\
\text { AICc selected } \\
\text { model) }\end{array}$ & 1.08 & 0.68 & 1.71 & 0.740 \\
\hline
\end{tabular}


Table 3. Binomial generalised linear mixed effect models of predation against daily visitors with model AICc values and weights. The grouped predator models consider all predator visits together while the individual predator models consider them separately. The null model includes only the intercept and study week random effect. *indicates significance at the $95 \%$ level.

\begin{tabular}{|c|c|c|c|c|c|c|c|}
\hline $\begin{array}{l}\text { Predator } \\
\text { variables }\end{array}$ & Model & $\begin{array}{l}\text { Visit } \\
\text { Coefficients }\end{array}$ & $\begin{array}{l}\text { Estimate } \\
\text { (95\% CIs) }\end{array}$ & $\begin{array}{l}\text { Std. } \\
\text { Error }\end{array}$ & $\mathrm{P}$ & $\begin{array}{l}\text { Model } \\
\text { AICc }\end{array}$ & $\begin{array}{l}\text { Model } \\
\text { weight }\end{array}$ \\
\hline \multirow{4}{*}{$\begin{array}{l}\text { Grouped } \\
\text { predators }\end{array}$} & Null & Intercept only & $\begin{array}{l}0.751 \\
(-0.263-2.061)\end{array}$ & 0.4533 & 0.0976 & 84.1 & 0.024 \\
\hline & \multirow{2}{*}{ Global } & All Predators & $\begin{array}{l}0.079 \\
(0.022-0.155)\end{array}$ & 0.033 & $0.016^{*}$ & \multirow{2}{*}{79.4} & \multirow{2}{*}{0.255} \\
\hline & & All small birds & $\begin{array}{l}0.004 \\
(-0.012-0.021)\end{array}$ & 0.008 & 0.620 & & \\
\hline & $\begin{array}{l}\text { AICc } \\
\text { selected }\end{array}$ & All Predators & $\begin{array}{l}0.068 \\
(0.025-0.157)\end{array}$ & 0.029 & 0.019* & 77.3 & 0.705 \\
\hline \multirow{9}{*}{$\begin{array}{l}\text { Individual } \\
\text { predators }\end{array}$} & Null & Intercept only & $\begin{array}{l}0.751 \\
(-0.263-2.061)\end{array}$ & 0.4533 & 0.0976 & 84.1 & 0.024 \\
\hline & \multirow{3}{*}{ Global } & Squirrel & $\begin{array}{l}0.068 \\
(-0.004-0.141)\end{array}$ & 0.037 & 0.066 & \multirow{3}{*}{81.5} & \multirow{3}{*}{0.095} \\
\hline & & Magpie & $\begin{array}{l}0.131 \\
(-0.081-0.342)\end{array}$ & 0.108 & 0.225 & & \\
\hline & & All small birds & $\begin{array}{l}0.004 \\
(-0.012-0.020)\end{array}$ & 0.008 & 0.645 & & \\
\hline & Model 2 & Magpie & $\begin{array}{l}0.178 \\
(0.0197-0.414)\end{array}$ & 0.097 & 0.068 & 81.2 & 0.108 \\
\hline & \multirow{2}{*}{ Model 3} & Squirrel & $\begin{array}{l}0.084 \\
(0.017-0.174)\end{array}$ & 0.039 & $0.029 *$ & \multirow{2}{*}{80.9} & \multirow{2}{*}{0.124} \\
\hline & & All small birds & $\begin{array}{l}0.005 \\
(-0.010-0.219)\end{array}$ & 0.008 & 0.519 & & \\
\hline & \multirow[t]{2}{*}{ Model 4} & Squirrel & $\begin{array}{l}0.070 \\
(0.003-0.158)\end{array}$ & 0.038 & 0.063 & \multirow[t]{2}{*}{79.3} & \multirow[t]{2}{*}{0.277} \\
\hline & & Magpie & 0.061 & 0.084 & 0.469 & & \\
\hline
\end{tabular}




\begin{tabular}{|l|l|l|l|l|l|l|l|}
\hline & & $(-0.045-0.391)$ & & & & \\
\cline { 2 - 7 } & $\begin{array}{l}\text { AICc } \\
\text { selected }\end{array}$ & Squirrel & $\begin{array}{l}\text { 0.090 } \\
(\mathbf{0 . 0 2 2}-\mathbf{0 . 1 7 9 )}\end{array}$ & $\mathbf{0 . 0 3 9}$ & $\mathbf{0 . 0 2 1} *$ & $\mathbf{7 9 . 1}$ & $\mathbf{0 . 3 1 4}$ \\
\hline
\end{tabular}

